\title{
Does the familiarity bias hypothesis explain why there is no masked priming for "NO" decisions?
}

\author{
Sachiko Kinoshita • Dennis Norris
}

Published online: 12 November 2010

(C) The Psychonomic Society 2010

\begin{abstract}
Traditional "activation" views of masked priming explain the identity priming effect in terms of facilitation due to 'pre-activation' of stored representations. Norris and Kinoshita's (2008) Bayesian Reader theory of masked priming instead explains priming in terms of the evidence that the prime contributes towards the decision required to the target. In support of the Bayesian Reader account, Norris and Kinoshita showed that the absence of priming for nonwords in the lexical decision task and for targets requiring a Different decision in the same-different match task can be explained based on a single principle. Against this, Bowers (2010) argued that the absence of priming should be explained instead by a combination of sublexical priming and "familiarity bias". As evidence, Bowers cited Bodner and Masson's (1997) finding that nonword priming did emerge with targets presented in visually unfamiliar cAsE-AlTeRnAtEd format. We present evidence that this finding was due to the use of an ambiguous letter in casealternated format; when using unambiguous letters, we consistently failed to find priming of case-alternated nonwords. We suggest that the Bayesian Reader, rather than the familiarity bias hypothesis, explains the absence of priming.
\end{abstract}

Keywords Masked priming - Lexical decision ·

Same-different task - Bayesian reader Familiarity bias

\author{
S. Kinoshita $(\bowtie)$ \\ Macquarie Centre for Cognitive Science (MACCS) \\ and Department of Psychology, Macquarie University, \\ Sydney, NSW 2109, Australia \\ e-mail: sachiko.kinoshita@mq.edu.au \\ D. Norris \\ MRC Cognition and Brain Sciences Unit, \\ 15 Chaucer Road, \\ Cambridge CB2 7EF, UK \\ e-mail: dennis.norris@mrc-cbu.cam.ac.uk
}

\section{Introduction}

Masked priming is a popular procedure for investigating automatic aspects of visual word recognition (for a survey of this literature, see Kinoshita \& Lupker, 2003). As noted recently by Grainger (2008, p.8), an "overview of research on orthographic processing would not be complete" without mention of this procedure. In masked priming, responses to a target word preceded by an identical prime (e.g., table$T A B L E)$ are facilitated relative to a target preceded by a prime that is completely different from the target (e.g., floor-TABLE). Priming occurs despite the fact that the prime is presented briefly and backward-masked so that participants are generally unaware of its presence, let alone its identity (Forster \& Davis, 1984). This identity priming effect is found across a range of word recognition tasks, such as lexical decision and semantic categorization (for a review, see Forster, Mohan, \& Hector, 2003).

One important characteristic of masked priming in the lexical decision task, arguably the most popular task used in studies of visual word recognition, is that it is specific to word targets; priming for "nonword" decisions is usually weak or non-existent. Forster (1998) reported that in a survey of 40 experiments, the mean size of nonword priming was only $8.7 \mathrm{~ms}$, and only in three cases was priming for nonword targets statistically significant at the 0.05 level.

Traditionally, this absence of priming has been interpreted in terms of lexical activation (e.g., Davis, 2003). A masked prime is assumed to automatically activate its corresponding representation in the internal lexicon. When the target is identical to the prime, it therefore gets a headstart. In contrast, by definition, nonwords do not have lexical representations. Because there is nothing to "preactivate', nonword targets do not show priming. However, 
as we will see shortly, this view of masked priming faces a problem in explaining masked priming effects observed in other tasks.

\section{The Baysian reader account of masked priming}

Recently, Norris and Kinoshita (2008) proposed an alternative account of masked priming based on the Bayesian Reader model of visual word recognition (Norris, 2006). The Bayesian Reader attempts to make optimal decisions based on the accumulation of noisy evidence. To explain masked priming, we made an additional assumption. In common with another Bayesian account of short-term priming proposed by Huber and colleagues (Huber, Shiffrin, Lyle, \& Quach, 2002; ROUSE-Responding Optimally with Unknown Source of Evidence model), we assumed that the masked prime is not treated as a separate perceptual event, but that evidence from the prime is integrated with the target ("not discounted" in the terminology of Huber et al.). Evidence from the prime therefore contributes to the decision required to the target. Within this account, unlike the traditional view, the pattern of priming does not depend on activation of a stored representation; instead, it depends on the decision required by the task.

As predicted by this view, Norris and Kinoshita (2008) showed that the pattern of priming can be radically different in different tasks. They used the same prime-target pairs in both a lexical decision task, and in a same-different match task. In this task, participants are first presented with a reference item (hereafter called the "referent") for $1 \mathrm{sec}$ together with a forward mask for the prime, followed by a prime, and then a target stimulus, which also acts as a backward-mask for the prime. The forward mask-primetarget sequence is identical to that in a lexical decision task (as developed by Forster \& Davis, 1984). The subject's task is to decide whether the target stimulus is the same as, or different from, the referent. In their lexical decision experiment Norris and Kinoshita replicated the standard finding that there was priming for words but not for nonwords. However, in the same-different task they found that there was priming for Same responses, but not for Different responses, regardless of whether the targets were words or nonwords. Such a finding is clearly at odds with the traditional "lexical activation" view, but is predicted by the Bayesian Reader, as confirmed by simulations.

In the Bayesian Reader the prediction that there should be no priming for nonwords in lexical decision and no priming for Different responses in the same-different task, both follow from the same principle. This is perhaps easiest to appreciate by first considering the same-different task. The decision required to perform this task is: "Is the target the same as the referent or different?". An identity prime for a "same" target (e.g., where the referent is 'fist', the prime "fist', and the target is 'FIST') will contribute evidence supporting a decision that the target is the same as the referent. An unrelated prime will contribute to a different decision. There will therefore be an overall priming effect when comparing identity and unrelated primes for Same targets. Now consider the case of an "identity prime" for a different target (e.g., where the referent is 'page', the prime 'fist' and the target is 'FIST'). The evidence from the prime 'fist' supports the hypothesis that the target is different from the referent. However, the unrelated prime 'ship' would provide equally strong evidence that the target is not 'page'. Because the model does not need to evaluate a hypothesis about the specific form of a different target, there is no need to accumulate evidence as to its identity. The task is simply to classify the target as same or different, and the specific identity of different targets has no bearing on this decision.

An analogous argument applies to lexical decision. In the Bayesian Reader, both the same-different task and lexical decision task involve comparison of input with a set of items held in memory. In the same-different task, the task is to decide whether the target is the same as the referent, or different. In lexical decision the task is to decide whether the target is the same as the set of words contained in the lexicon, or different. Computationally, the only distinction between the two tasks is that in lexical decision the set of items involved in the comparison is stored in the lexicon, and in the same-different task the set consists solely of the one referent which has just been presented. Hence, priming in the same different task patterns like lexical decision, but with the Same items behaving like words, and the Different items behaving like nonwords. A nonword prime will contribute evidence that the nonword is not a word, only indirectly mediated by lexical representation, and the target will contribute more evidence. That is, Same responses in the same-different task should pattern like words in lexical decision, and Different responses like nonwords.

\section{The familiarity bias hypothesis}

In a recent commentary on the Bayesian reader account of masked priming, Bowers (2010) suggested that the absence of masked priming for nonwords (in lexical decision) and Different responses (in the same-different task) can be explained instead by the notion of "familiarity bias". The idea that the absence of masked priming effect for nonwords in lexical decision could be explained by familiarity bias was originally proposed by Bodner and Masson (1997). They suggested that masked priming enhances perceptual fluency, which in turn leads subjects to experience a feeling of familiarity for the target. In 
lexical decision, this increased sense of familiarity produces a bias to respond 'Word' (given that familiar letter strings tend to be words) which enhances the priming effect. In contrast, for nonword targets, the benefit due to enhanced perceptual fluency is counteracted by the bias to respond 'Word'. Consequently, there is no net priming effect for nonwords. This fits nicely with the fact that in lexical decisions, masked priming effects for nonwords are generally weak and often non-existent. Bowers (2010) extended the notion of familiarity bias to explain the absence of priming for Different responses in the samedifferent task. A masked prime improves the perception of the target, but this improved fluency is taken as evidence that the target has been repeated (i.e., the target is the same as the referent). This bias produces facilitation of Same decisions, but interferes with Different decisions. So, for both 'nonword' decisions in lexical decision and for Different decisions in the same-different match task, the familiarity bias exactly cancels out the benefit due to enhanced perceptual fluency generated by masked priming.

In support of the familiarity bias hypothesis, Bodner and Masson (1997) showed that the size (and direction) of masked priming for nonwords in lexical decision can vary, using two types of manipulation. One manipulation involved nonword type. In Bodner and Masson's (1997) Experiment 3, the nonwords were all pseudohomophones (nonwords which are pronounced like a real word, e.g., reer, celf). In this experiment, a large nonword priming effect $(38 \mathrm{~ms})$ was observed. In their Experiment 4, all word targets were high-frequency words and the nonword targets were consonant strings (e.g., TWLT, SHTGS). In this experiment, masked priming effect for words was much smaller than usual (22 $\mathrm{ms}$ ), and a reverse priming effect (-9 ms) was found for nonwords. What should be noted about these demonstrations, however, is that: (1) the familiarity bias hypothesis is not the only account to predict a variation in the size of priming and (2) the reversal in the direction of priming effect for orthographically illegal nonwords has not been replicated (Forster, Mohan and Hector 2003; Experiment 1).

Pseudohomophones are generally assumed to be sufficiently similar to the basewords (e.g., rear, self), such that they require a detailed comparison between the spelling of the nonword and the corresponding baseword before the target can be correctly classified as a nonword (see Yap, Balota, Tse, \& Besner, 2008; Yap, Tse, \& Balota, 2009). If this were the case, then nonword priming similar in size to word priming may have emerged because both word and nonword targets called for the retrieval of a specific lexical representation (of baseword in the case of nonwords), rather than because familiarity bias was abandoned.

Bodner and Masson's (1997) Experiment 4 used orthographically illegal nonwords (consonant strings) and high- frequency words as stimuli, and found a smaller-than-usual priming effect with word targets, and a reverse nonword priming effect. The smaller-than-usual priming effect with word targets was replicated by Forster, Mohan and Hector (2003; Experiment 1) also using consonant-string nonwords. However, they did not replicate the reverse priming effect. Instead they found a null priming effect $(2 \mathrm{~ms})$ for their nonwords, just as in typical lexical decision experiments. It may also be noted that the reverse priming effect of 9 ms reported by Bodner and Masson (1997), which they took as a reversal in the direction of priming, is similar in size to the (statistically non-significant) $-7 \mathrm{~ms}$ effect they observed with the orthographically legal nonwords (e.g., $F E A P, B R E E M)$ in their Experiment 1. Taken together, there is little evidence to support the claim that when orthographically illegal nonwords are used, this tips the balance in favor of greater reliance on the subjective feeling of familiarity.

More broadly, the effects of wordlikeness of nonwords on the lexical decision process are well-accounted for by models that do not assume a role for familiarity bias. For example, Ratcliff, Gomez, and McKoon (2004) provided an account of the entire RT distribution, not just mean RT, as a function of nonword type (orthographically legal nonwords vs. random letter strings) based on the drift-diffusion model (see also Norris, 2009, for a reinterpretation of the Ratcliff et al. data as a variant of a Bayesian diffusion model, and Wagenmakers, Steyvers, Raaijmakers, Shiffrin, van Rijn \& Zeelenberg, 2004, for a Bayesian model of a signal-torespond version of the lexical decision task). As noted, a key assumption of the Bayesian Reader account is that priming depends on the nature of the decision required by the task. From this perspective, the finding that the size of priming can vary as a function of nonword type does not provide exclusive support for the familiarity bias hypothesis.

In contrast, the second manipulation used by Bodner and Masson (1997) provides more direct support for the familiarity bias hypothesis. In their Experiment 2a nonword priming emerged when the targets were presented in cAsEAlTeRnAtEd format. In this paper, we focus on this demonstration.

The outline of the paper is as follows. We first describe Bodner and Masson's (1997) case-alternation experiment, the logic of the experiment and the results, and consider an alternative interpretation which explains the priming effect for nonwords in terms of physical continuity between the letters of the prime and target. Experiment 1 tests this interpretation. The results lend little support for the physical continuity hypothesis, but they also show that the finding of nonword priming is confined to only some of Bodner and Masson's stimuli. Experiment 2 and 3 use a new set of stimuli in both the lexical decision task and in the samedifferent task to test whether presenting the target in case- 
alternated format is sufficient to produce nonword priming. The results do not support the familiarity bias prediction. We close with a discussion of conditions under which enhanced perceptual fluency due to masked priming may be misattributed, and conclude that the typical conditions under which lexical decision and the same different task are performed do not meet these conditions.

\section{Bodner and Masson's (1997) cAsE-aLtErNaTiOn experiment}

The key assumption of the familiarity bias hypothesis is the role it assigns to the subjective sense of familiarity. Bodner and Masson (1997; Experiment 2) attempted to reduce the contribution of familiarity by presenting targets in casealternated format. They reasoned that nonword priming should emerge for these targets because the lack of visual familiarity should "reduce subject's dependence on an immediate sense of familiarity in classifying the target" (p. 275), consequently reducing the contribution of subjective bias toward responding "Word" to familiar items. Bodner and Masson also predicted that making target identification difficult by means of the case-alternation manipulation would increase the priming effect overall because it should "force subjects to rely more heavily on information available from the prime to make their response" (p. 275). The results were consistent with both of these predictions. In their Experiment 1 in which targets were presented in the uppercase format, the priming effects were $29 \mathrm{~ms}, 45 \mathrm{~ms}$ and $-7 \mathrm{~ms}$ for high-frequency words, low-frequency words, and nonwords, respectively; in their Experiment $2 \mathrm{~b}$ using the same targets presented in casealternated format, the priming effects increased to $71 \mathrm{~ms}$, $79 \mathrm{~ms}$, and $93 \mathrm{~ms}$, respectively.

There are a couple of reasons for questioning this finding, however. The first concerns its replicability: Both the finding of an overall increase in the size of masked priming effect, and the emergence of nonword priming for case-alternated targets, may be exceptional. In a different study, Bodner and Masson (2001) presented high-frequency word and nonword targets in uppercase format (Experiment $5 a)$ and case-alternated format (Experiment 5b). They noted that there was no priming for nonwords in either experiment; also, their data did not show that case alternation increased the size of priming overall.

Second, the emergence of priming for case-alternated nonwords has an alternative explanation, which has not been tested. The alternative suggests that the priming effect observed with case-alternated nonword targets is due to the physical continuity in some of the letters of the prime and target. Bodner and Masson (1997) presented the prime in lowercase letters and the target in case-alternated format in the same font as the prime. This means that the lowercase letters of target was physically continuous with (half of) the corresponding letters of their identity prime (e.g., the "w" and " $\mathrm{r}$ " in the pair word-wOrD). Physical continuity amounts to starting the RT clock later, by the amount corresponding to the prime duration, so for all targets, words or nonwords, an identity priming effect equal to the prime duration should emerge. ${ }^{1}$ Data consistent with this effect of physical continuity between the prime and target can be found in an experiment by Marzouki and Grainger (2008). They varied whether the prime and target were presented at the same physical location. Primes and targets were presented in the same lower-case font and in the samesize. When they were presented in the same physical location, they found that priming for nonwords was the same size as priming for word targets. Their finding raises the possibility that, perhaps in Bodner and Masson's (1997) Experiment 2a, it was not the unfamiliar visual format of the case-alternated targets that made subjects abandon familiarity bias, but instead it was the physical continuity between half of the letters in the prime and target that was responsible for the emergence of priming effect for nonwords.

In Marzouki and Grainger (2008), when primes and targets were presented in the same location, all of the letters in the prime and target were physically continuous. In Bodner and Masson's (1997) Experiment 2a, half of the letters in the prime and target were physically continuous. Whether this is sufficient to produce priming for nonwords is an open question, and this is what was investigated in Experiment 1.

\footnotetext{
${ }^{1}$ Bodner and Masson (1997) were aware of the potential problem due to physical continuity and conducted Experiment $2 \mathrm{~b}$ as a control experiment. In this experiment, the non-overlapping letters of identity primes were replaced with different letters (e.g., word-wOrD became wirk-wOrD). Their rationale was that if the identity priming effect observed with the case-alternated nonwords was due to the physical continuity of (half of) the letters, then the same pattern of priming should be observed in the control experiment. They took the absence of priming (with either words or nonwords) in this experiment as evidence against the physical continuity hypothesis. What should be noted, however, is that the rationale of the control experiment rests on the assumption that sublexical/letter-level priming was responsible for identity priming, and that this also produces priming with two-lettersubstituted primes. In fact, when targets are presented in the standard uppercase format, two-letter-substituted primes (e.g., wirk-WORD) do not produce priming in the lexical decision task, at least for words of length 4- to 6-letters as used by Bodner and Masson (e.g., Norris, Kinoshita, \& van Casteren, 2010, Experiment 1; Perea \& Lupker, 2003, Experiments 2, 3; Schoonbaert \& Grainger, 2004, Experiment 4). Given this, the finding of null priming in the control experiment does not rule out the possibility that physical continuity between some of the letters was responsible for the identity priming effect observed with case-alternated nonwords in Bodner and Masson's (1997) Experiment 2a.
} 


\section{Experiment 1 (lexical decision with Bodner \& Masson's stimuli)}

In Experiment 1, we tested the physical continuity hypothesis by presenting all targets in case-alternated format, and manipulating the prime font. For half of the trials, the prime was presented in the same font as the target so that for the identity prime, half of the letters were physically continuous with the target (e.g., the letters $\mathrm{u}, \mathrm{h}$ and $\mathrm{r}$ in usher - uShEr), just as in Bodner and Masson (1997, Experiment 2a). For the other half of trials, the prime was presented in a different font (Arial 10) so that there was no physical continuity between the letters of the identity prime and target (e.g., tree - tReE, usher - uShEr). According to the physical continuity hypothesis, such nonword priming effect is expected with the same-font primes (for which there is physical continuity) but not with the different-font primes.

\section{Method}

Participants Thirty-two psychology students from Macquarie University participated in Experiment 1 in return for course credit.

\section{Design}

Experiment 1 used the lexical decision task, and used a 2 (Prime type: Identity vs. Control) x 2 (Prime font: Same vs. Different) x 2 (Response: Word vs. Nonword) factorial design, with all factors manipulated within subjects. The dependent variables were decision latency and error rate.

\section{Materials}

The critical stimuli were 96 words and 96 nonwords used by Bodner and Masson (1997; Experiment 2a), which contained an equal number of 4-letter, 5-letter and 6-letter items. Half of the words were high-frequency (40-60 occurrences per million; Kucera \& Francis, 1967) such as tree and smile; half were low-frequency (1-2 per million) such as ajar and usher. Nonwords were all orthographically legal and pronounceable, such as bream and feap.

In Experiment 1, all targets were presented in casealternated format, in Courier 12 font. As in Bodner and Masson's (1997) Experiment 2a, the initial letter was always in lowercase. Each target was paired with four types of primes, resulting from a factorial combination of Prime type and Prime font. The Identity prime was the same word as the target, e.g., tree-tReE. The control prime was an item from the same frequency band and lexical class, e.g., sell-tReE, melon-uShEr, sude-fEaP. The control primes shared no more than two, and usually shared zero, letters with the target and the shared letters were not in the same position. Within each of the Identity and Control prime conditions, the prime was either presented in the same font as the target (Same-font condition, e.g., tree-tReE, selltReE), or in Arial 10 font (different-font condition, e.g., tree-tReE, sell-tReE). The critical target words and primes are listed in the Appendix of Bodner and Masson (1997).

The stimuli were divided into four sets, matched on mean frequency (for word targets) and length. Four list versions were constructed for the purpose of counterbalancing assignment of sets to the four prime types, so that within a list, each target word occurred only once, and across the four lists, appeared in each of four prime conditions once. An equal number of participants were assigned to the four list versions.

In addition, there were 12 practice and initial buffer items, selected according to the same criteria as the test stimuli. These items were not included in the analysis.

Apparatus and procedure

Participants were tested in groups of 1-6, seated approximately $40 \mathrm{~cm}$ in front of a CRT monitor, upon which stimuli were presented. Each participant completed 192 test trials consisting of 96 Word and 96 Nonword trials, presented in two half-blocks with a self-paced break between the blocks. A different random order was generated for each participant.

Participants were instructed at the outset of the experiment that on each trial they would be presented with a letter string, and their task was to decide whether it was a real word or not, as fast and accurately as possible. No mention was made of the presence of the prime. They were instructed to press a key on a response pad marked "+" for Word and a key marked "_" for Nonword responses.

Stimulus presentation and data collection were achieved through the use of the DMDX display system developed by K.I. Forster and J.C. Forster at the University of Arizona (Forster \& Forster, 2003). Stimulus display was synchronized to the screen refresh rate $(13.3 \mathrm{~ms})$.

Each trial started with the presentation of a forward mask consisting of 6 \# signs for $500 \mathrm{~ms}$. The mask was replaced by the prime in lowercase letters presented for $53 \mathrm{~ms}$. The prime was in turn replaced by the target presented in case-alternated format (always starting with a lowercase letter) for a maximum of 2,000 ms, or until the participant's response. Participants were given feedback ("Wrong response" message on the screen) only when they made an error on a trial.

\section{Results and discussion}

For this and subsequent experiments, the preliminary treatment of trials was as follows. Any trial on which a 
participant made an error was excluded from the analysis of RT. To reduce the effects of extremely long and short latencies, the cutoff was set for each participant at \pm 3 standard deviations (SDs) from each participant's mean latency and responses faster or slower than the cutoff were replaced with the corresponding cutoff value. In Experiment 1 , this affected $1.5 \%$ of trials. We first report the analyses for words and nonwords separately, each using a two-way analysis of variance (ANOVA) with Prime type (Identity vs. Control) and Prime font (Same or Different) as factors. We also test the interaction between priming and response type to see if the size of priming differed for words and nonwords. Effects were considered to be significant when both subject and item analyses were significant at the 0.05 level. Mean response latencies and error rates are presented in Table 1.

\section{Word responses}

For latency, the main effect of prime type was significant, $\mathrm{F}_{1}(1,27)=101.40, \mathrm{MSe}=832.08 ; \mathrm{F}_{2}(1,92)=42.68, \mathrm{MSe}=$ 10052.99. (Degrees of freedom for the error term for latency in the by-items analysis was 92 rather than 95 , because 3 items had an error rate of $100 \%$ and did not contribute latency data in one of the prime conditions). Averaged over prime font, there was a priming effect of $55 \mathrm{~ms}$. The main effect of prime font was non-significant, $\mathrm{F}_{1}<1.0 ; \mathrm{F}_{2}<1.0$. The two factors did not interact, $\mathrm{F}_{1}<$ $1.0 ; \mathrm{F}_{2}<1.0$.

For error rate, the main effect of prime type was significant, $\mathrm{F}_{1}(1,27)=14.73, \mathrm{MSe}=60.66 ; \mathrm{F}_{2}(1,95)=$ $20.58, \mathrm{MSe}=149.00$. The main effect of prime font was non-significant, $\mathrm{F}_{1}<1.0 ; \mathrm{F}_{2}<1.0$. There was no interaction between the two, $\mathrm{F}_{1}<1.0 ; \mathrm{F}_{2}<1.0$.

\section{Nonword responses}

For latency, the main effect of prime type was significant, $\mathrm{F}_{1}(1,27)=8.61, \mathrm{MSe}=2386.76 ; \mathrm{F}_{2}(1,95)=4.89, \mathrm{MSe}=$ 7218.05. Averaged over prime font, there was a priming effect of $27 \mathrm{~ms}$. The main effect of prime font was nonsignificant, $\mathrm{F}_{1}<1.0 ; \mathrm{F}_{2}<1.0$. The two factors did not interact, $\mathrm{F}_{1}<1.0 ; \mathrm{F}_{2}<1.0$.

For error rate, none of the main or interaction effects were significant, i.e., all $\mathrm{F}<1.0$.

Priming $\mathrm{x}$ response interaction

As evidenced by the statistically significant interaction, $\mathrm{F}_{1}(1,27)=7.48$, MSe $=1446.73$ and $\mathrm{F}_{2}(1,187)=13.03$, MSe $=8612.78$, the size of priming was considerably smaller for nonword targets than word targets. In contrast to Bodner and Masson's (1997) Experiment 2a, which showed a nonword priming effect $(93 \mathrm{~ms})$ that was as large (if not larger) than for words $(75 \mathrm{~ms})$, the effect for the comparable same-font conditions was $25 \mathrm{~ms}$ for nonwords and $49 \mathrm{~ms}$ for words.

\section{Discussion}

The results of Experiment 1 did not provide support for the physical continuity hypothesis. Contrary to its prediction, nonword priming was not limited to the same-font primes: The same-font and different-font primes showed a similarsize priming effect for nonwords. The results suggest that when half of the letters in the identity-prime and target differ in case, the prime and target are not perceived as physically continuous. ${ }^{2}$

The results are more consistent with the familiarity bias hypothesis. As expected from this hypothesis, a priming effect for nonwords did emerge with case-alternated targets, and this was found with both the same-font and differentfont primes. However, the results did not completely replicate the pattern reported by Bodner and Masson (1997). Unlike their Experiment 2a, the size of priming effect was considerably smaller for nonwords than for words, and priming for both words and nonwords was much smaller than that observed by Bodner and Masson. As we used exactly the same case alternation procedure and used their stimuli, this was unexpected. Recall also that this is not the first study that did not replicate the pattern reported by Bodner and Masson (1997). Bodner and Masson (2001, Experiment 5b) did not find priming for nonwords presented in case-alternated format. This lack of consistency was a concern, and we considered whether factors other than the assumed reduction in subjective familiarity could have caused the case-alternated nonwords to show priming here.

From the perspective of the Bayesian Reader, a nonword priming effect might be expected if it was due to letter priming. One potential source of this with case-alternated targets is letter ambiguity. Specifically, when uppercase and lowercase letters are alternated, the lowercase letter 1 and the uppercase letter I are difficult to distinguish. Evidence accumulated from the abstract letter identities of the identity prime (i.e., with the different-font identity prime as well as the same-font identity prime) may have contributed towards resolving this ambiguity and produced letter priming. To test this possibility, we analyzed the size of priming for case-alternated targets with and without letter ambiguity (operationally defined as targets that did

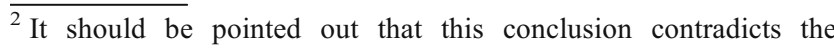
interpretation put forward by Kinoshita and Norris (2009b, footnote 1) of Bodner and Masson's (1997, Experiment 2a) finding.
} 
Table 1 Mean decision latencies (RT, in ms), standard error (in parentheses) and percent error rates $(\% \mathrm{E})$ in Experiment 1 (lexical decision task, Bodner \& Masson's stimuli)

Targets were always in Courier 12 font. The Same-font primes were in Courier 12 font; Different-font primes were in Arial 10 font
Response

\begin{tabular}{|c|c|c|c|c|c|c|}
\hline \multirow[b]{2}{*}{ Prime type } & \multicolumn{3}{|l|}{ Word } & \multicolumn{3}{|l|}{ Nonwords } \\
\hline & Example & RT & $\% \mathrm{E}$ & Example & RT & $\% \mathrm{E}$ \\
\hline Target & SUITrY & & & lOvInK & & \\
\hline Same-font identity & sultry & $593(17)$ & 14.6 & lovink & $721(23)$ & 11.6 \\
\hline Same-font control & grovel & $642(17)$ & 20.5 & triner & $746(23)$ & 12.8 \\
\hline Priming effect & & 49 & 5.9 & & 25 & 1.2 \\
\hline Different-font identity & sultry & $591(14)$ & 14.1 & lovink & $719(21)$ & 13.2 \\
\hline Different-font control & grovel & $651(19)$ & 19.5 & triner & $748(22)$ & 12.9 \\
\hline Priming effect & & 60 & 5.4 & & 29 & -0.3 \\
\hline
\end{tabular}

and did not contain the lowercase letter "l", e.g., sUlTrY is ambiguous, but aMuLeT is unambiguous; IOvInK is ambiguous, bLyNeR is unambiguous). The mean response latencies and error rates for unambiguous and ambiguous stimuli are shown in Table 2.

ANOVA of RTs and error rates were conducted for words and nonwords separately with prime font (same vs. different), prime type (identity vs. control) and letter ambiguity (ambiguous vs. unambiguous) as factors.

\section{Word responses}

For latency, the only significant effect was the main effect of prime type, $\mathrm{F}_{2}(1,91)=42.64, \mathrm{MSe}=10117.44$. All other main and interaction effects were non-significant, i.e., all $\mathrm{F}<1.0$. Notably, there was no main or interaction effect involving the letter ambiguity factor.

For error rate, there was a main effect of prime type, $\mathrm{F}_{2}(1,94)=20.38, \mathrm{MSe}=150.57$, and an interaction between letter ambiguity and prime font, $\mathrm{F}_{2}(1,94)=6.17$, MSe $=252.97$. This interaction reflected the fact that whereas for words containing an ambiguous letter, a different-font prime (either control or identity) increased the error rate, for words containing unambiguous letters, it decreased the error rate.

\section{Nonword responses}

For latency, the main effect of prime type was significant, $\mathrm{F}_{2}(1,94)=8.23, \mathrm{MSe}=6952.37$. The main effect of letter ambiguity was also significant, $F_{2}(1,94)=9.27$, MSe $=$ 15879.60, as was the interaction between letter ambiguity and prime type, $\mathrm{F}_{2}(1,94)=4.63$, $\mathrm{MSe}=6952.37$. That is, for nonwords, responses were significantly slower for ambiguous-letter items (by $42 \mathrm{~ms}$ ), and the priming effect was magnified for these stimuli. The $46 \mathrm{~ms}$ priming effect for ambiguous nonwords was significant, $\mathrm{t}_{2}(30)=3.20, p=$ 0.003 , but the $7 \mathrm{~ms}$ priming effect for unambiguous nonwords was non-significant, $\mathrm{t}_{2}(64)=0.61, p=0.54$. No other main or interaction effect was significant, all $F<1.48, p>0.23$.

For error rate, no main or interaction effects were significant, i.e., all $\mathrm{F}<1.0$.
Table 2 Mean decision latencies (RT, in ms), standard error (in parentheses) and error rates for unambiguous and ambiguous targets in Experiment 1

\begin{tabular}{lllll}
\hline Item type & & & & \\
\hline & Unambiguous & & Ambiguous & \\
Target type and prime type & Example RT & $\% \mathrm{E}$ & Example RT & $\% \mathrm{E}$ \\
\hline Word & wEaPoN $(N=47)$ & & $1 \mathrm{IsTeN}(N=49)$ & \\
Same-font identity & $587(16)$ & 16.4 & $606(15)$ & 12.8 \\
Same-font control & $659(21)$ & 21.0 & $673(20)$ & 20.1 \\
Different-font identity & $599(18)$ & 10.3 & $612(17)$ & 17.8 \\
Different-font control & $677(23)$ & 17.3 & $668(22)$ & 21.6 \\
Priming effect & 75 & 5.8 & 61 & 5.5 \\
Nonword & $\mathrm{jAsAnT}(N=65)$ & & $1 \mathrm{OvInK}(N=31)$ & \\
Same-font identity & $719(13)$ & 12.3 & $739(19)$ & 10.1 \\
Same-font control & $716(11)$ & 13.9 & $796(18)$ & 10.6 \\
Different-font identity & $716(12)$ & 12.8 & $741(17)$ & 14.3 \\
Different-font control & $732(12)$ & 13.4 & $776(17)$ & 12.0 \\
Priming effect & 7 & 1.1 & 46 & -0.9 \\
\hline
\end{tabular}


These analyses show that priming for case-alternated nonwords is limited to targets containing an ambiguous letter. The fact that this did not interact with prime font suggests that the priming effect was not based on the physical continuity of letters, but on abstract letter representations. For word targets, letter ambiguity affected neither the RT nor the size of priming, perhaps because, in the case of words, other letters within the word (i.e., the word context) could be used to resolve the ambiguity.

In summary, with case-alternated targets, priming for nonwords was observed, with both the same-font primes and different-font primes. This result was not expected from the physical continuity hypothesis. However, the fact that nonword priming was limited to targets containing an ambiguous letter, and no priming was observed with unambiguous nonwords, suggests that the emergence of priming for nonwords was not because the unfamiliar visual format of case-alternated targets led subjects to abandon the familiarity bias.

\section{Experiment 2 (lexical decision task)}

The results of Experiment 1 showed that using casealternated stimuli as targets, nonword priming was found. However, the fact that the emergence of priming was confined to targets containing an ambiguous lowercase letter 1 questions whether it was due to the reduced dependence on the subjective sense of familiarity caused by the unusual visual format. To provide a better test of the familiarity bias hypothesis, we generated a new set of stimuli that did not contain an ambiguous letter, and used them as targets in the lexical decision task (Experiment 2) and the same-different task (Experiment 3). If the absence of priming for nonwords and for Different responses is due to the familiarity bias, and if case alternation reduces the reliance on the subjective feeling of familiarity, then priming should emerge for nonword targets in lexical decision and for Different response in the same-different task. In contrast, the Bayesian Reader predicts priming for the word targets, but not for nonwords in the lexical decision task, and for the Same responses but not for the Different responses in the samedifferent task.

\section{Method}

Participants

An additional 28 psychology students from the same subject population as in Experiment 1 participated in Experiment 2.
Design

The design was identical to Experiment 1.

\section{Materials}

The critical stimuli were 80 seven-letter words and 80 seven-letter nonwords, generated in the following way. First, a set of words were selected from the English Lexicon Project Database (Balota et al., 2007; available at http:// elexicon.wustl.edu/), on the basis that the mean lexical decision accuracy was no lower than 0.88 (mean 0.97). This was to ensure that the stimuli were known to participants as words. From this set, 160 words that did not contain the letter "l" in the first, third, fifth or the seventh position were selected. This was to avoid the confusion between the letter 1 and I when presented in case-alternated format. The words ranged in frequency from 20 to 210 occurrences per million (Kucera \& Francis, 1967), with a mean of 59 per million. As expected of long words, most were "hermits", i.e., had no orthographic neighbours (0-2, mean .35), as defined in terms of Coltheart's N metric (Coltheart, Davelaar, Jonasson, $\&$ Besner, 1977). Eighty of the words were then used as word targets, and nonword targets were generated from the other 80 words by changing one or more consonants (e.g., porfing from morning, smienge from science). All nonwords were orthographically legal and pronounceable. The stimuli are presented in Appendix A. ${ }^{3}$

Apparatus and procedure

Apparatus, procedure, timing characteristics and the general instruction to subjects were all identical to Experiment 1.

\section{Results and discussion}

The preliminary treatment of data was identical to Experiment 1 , and the cut-off procedure affected $1.6 \%$ of trials. The analysis of data was identical to that of Experiment 1 . Mean response latencies and error rates are presented in Table 3.

\section{Word responses}

For latency, the main effect of prime type was significant, $\mathrm{F}_{1}(1,27)=118.14, \mathrm{MSe}=996.96 ; \mathrm{F}_{2}(1,79)=87.57, \mathrm{MSe}=$

\footnotetext{
${ }^{3}$ Due to experimenter error, the word balance (which contains the lowercase "l" in the case-alternated version) was included as a word target in Experiment 2 and a target requiring the Same response in Experiment 3. As the critical question concerned priming for nonwords and targets requiring a Different response, this item was not excluded from analysis.
} 
Table 3 Mean decision latencies (RT, in ms), standard error (in parentheses) and percent error rates $(\% \mathrm{E})$ in Experiment 2 (lexical decision task, all unambiguous-letter stimuli)

Targets were always in Courier 12 font. The Same-font primes were in Courier 12 font; Different-font primes were in Arial 10 font
Response

\begin{tabular}{|c|c|c|c|c|c|c|}
\hline \multirow[b]{2}{*}{ Prime type } & \multicolumn{3}{|l|}{ Word } & \multicolumn{3}{|l|}{ Nonword } \\
\hline & Example & RT & $\% \mathrm{E}$ & Example & RT & $\% \mathrm{E}$ \\
\hline Target & cEnTuRy & & & pOrFing & & \\
\hline Same-font identity & century & $496(12)$ & 1.6 & porfing & $601(17)$ & 5.4 \\
\hline Same-font control & supreme & $567(13)$ & 4.8 & trosect & $616(18)$ & 5.4 \\
\hline Priming effect & & 71 & 3.2 & & 14 & 0.0 \\
\hline Different-font identity & century & $505(12)$ & 2.1 & porfing & $619(18)$ & 4.8 \\
\hline Different-font control & supreme & $563(13)$ & 5.3 & trosect & $628(17)$ & 3.9 \\
\hline Priming effect & & 59 & 3.2 & & 9 & -0.9 \\
\hline
\end{tabular}

4103.28. Averaged over prime font, the priming effect was $65 \mathrm{~ms}$. The main effect of prime font was nonsignificant, $\mathrm{F}_{1}<1.0 ; \mathrm{F}_{2}<1.0$. The two factors did not interact, $\mathrm{F}_{1}(1,27)=1.83$, MSe $=544.72 ; \mathrm{F}_{2}(1,79)<1.0$.

For error rate, the main effect of prime type was significant, $\mathrm{F}_{1}(1,27)=19.61, \mathrm{MSe}=14.75 ; \mathrm{F}_{2}(1,79)=$ 11.45, $\mathrm{MSe}=72.31$. The main effect of prime font was non-significant, $\mathrm{F}_{1}<1.0 ; \mathrm{F}_{2}<1.0$. There was no interaction between the two, i.e., $\mathrm{F}_{1}<1.0 ; \mathrm{F}_{2}<1.0$.

Nonword responses

For latency, priming did not reach statistical significance, $\mathrm{F}_{1}(1,27)=3.78, \mathrm{MSe}=982.10, p=0.06 ; \mathrm{F}_{2}(1,79)=1.33$, $\mathrm{MSe}=7310.54$. The 11-ms effect is similar in size to the 8.7-ms effect reported by Forster (1998) averaged over 30 lexical decision experiments. The main effect of prime font was significant by subjects, $\mathrm{F}_{1}(1,27)=8.74$, MSe $=$ 732.59 , but not by items, $\mathrm{F}_{2}(1,79)=2.45$, MSe $=7210.75$. The two factors did not interact, i.e., $\mathrm{F}_{1}<1.0 ; \mathrm{F}_{2}<1.0$.

For error rate, none of the main or interaction effects were significant, i.e., all $\mathrm{F}<1.92, p>0.18$.

The results were clear. As in numerous lexical decision studies presenting targets in standard format, when stimuli were presented in case-alternated format, priming was observed with word targets but not with nonwords.

\section{Experiment 3 (same-different task)}

Experiment 3 presented the same case-alternated targets used in Experiment 2 in the same-different task. According to Bowers (2010), presenting targets in a visually unfamiliar format should eliminate the familiarity bias (because all targets are now visually unfamiliar, and hence perceptual fluency is no longer diagnostic of whether the target is the same as the referent), and therefore priming effect should emerge for Different response. In contrast, the prediction according to the Bayesian Reader is that there should be priming for the Same responses but not for Different responses.

\section{Method}

Participants

An additional thirty-two psychology students from the same subject population as in previous experiments participated in Experiment 3.

Design

The design was identical to Experiment 2, except that instead of the lexical decision task, the same-different match task was used.

\section{Materials}

The critical stimuli were the 80 seven-letter words used as word targets in Experiment 2, and a further 80 seven-letter words which were the words used to generate nonword targets in Experiment 2. The former were used as targets requiring the Same response and the latter were used as targets requiring Different response in the same-different match task. In addition, 80 additional 7-letter words were selected according to similar criteria for the critical stimuli. These words were used as the referent for the Different trials. In pairing a reference word and the target word for these trials, effort was made to avoid pairs that shared letters in the same positions. The prime-target pairs for the Same trials were identical to the Word trials in Experiment 2. The prime-target pairs used in the Different trials are presented in Appendix B.

The task was a same-different match task. Each trial comprised three stimuli: a referent, a prime, and a target word. The referent and prime were always in lowercase, and the target was in case-alternated format. 
Apparatus and procedure

Apparatus, procedure, timing characteristics and the general instruction to subjects were all identical to previous experiments, except that the task was a same-different task, rather than lexical decision, and hence the trial sequence was slightly different.

Each trial started with the presentation of a referent $n$ lowercase letters, above the forward mask for $1 \mathrm{~s}$. At the same time that the referent disappeared, the forward mask was replaced by the prime in lowercase letters presented for $53 \mathrm{~ms}$. The prime was in turn replaced by the target presented in case-alternated format for a maximum of $2,000 \mathrm{~ms}$, or until the participant's response. Thus the prime-target sequence was identical to the lexical decision task.

Participants were instructed to press a key on a response pad marked "+” for Same and a key marked “_" for Different response. Feedback ("Wrong response" message on the screen) was given only when they made an error on a trial.

\section{Results}

The preliminary treatment of data was identical to Experiment 1 , and the cut-off procedure affected $1.4 \%$ of trials. The Same responses and Different responses were analyzed separately, and within each, the analysis was identical to that of Experiment 1. Mean response latencies and error rates are presented in Table 4.

\section{Same responses}

For latency, the main effect of prime type was significant, $\mathrm{F}_{1}(1,31)=447.17, \mathrm{MSe}=526.19 ; \mathrm{F}_{2}(1,79)=420.87, \mathrm{MSe}=$ 1462.19. Averaged over prime font, the priming effect was $86 \mathrm{~ms}$. The main effect of prime font was non-significant, $\mathrm{F}_{1}<1.0 ; \mathrm{F}_{2}<1.0$. The two factors did not interact, $\mathrm{F}_{1}(1,31)=3.20, \mathrm{MSe}=521.21 ; \mathrm{F}_{2}(1,79)=2.53, \mathrm{MSe}=1876.77$.

For error rate, the main effect of prime type was significant, $\mathrm{F}_{1}(1,31)=28.99, \mathrm{MSe}=62.10 ; \mathrm{F}_{2}(1,79)=$
70.66, MSe $=63.69$. The main effect of prime font was non-significant, $\mathrm{F}_{1}<1.0 ; \mathrm{F}_{2}<1.0$. There was no interaction between the two, i.e., $\mathrm{F}_{1}<1.0 ; \mathrm{F}_{2}<1.0$.

\section{Different responses}

For latency, none of the main or interaction effects were significant, all $\mathrm{F}<1.13, p>0.29$. Critically, there was no priming effect either for the same-font primes $(-1 \mathrm{~ms})$ or different-font primes $(-2 \mathrm{~ms})$.

For error rate, the main effect of prime type was nonsignificant, $\mathrm{F}_{1}(1,31)=2.16, \mathrm{MSe}=17.72 ; \mathrm{F}_{2}(1,79)=2.71$, $\mathrm{MSe}=35.38$. The main effect of prime font was significant, $\mathrm{F}_{1}(1,31)=6.05, \mathrm{MSe}=10.46 ; \mathrm{F}_{2}(1,79)=4.57, \mathrm{MSe}=34.59$. There was no interaction between the two, i.e., $\mathrm{F}_{1}<1.0 ; \mathrm{F}_{2}<1.0$.

The results are straightforward. Replicating many previous findings with targets presented in the standard format (Norris \& Kinoshita, 2008; Kinoshita, \& Norris, 2009, 2010), there was a large priming effect for the Same responses, but no priming for Different responses. The absence of priming for Different decisions is at odds with the familiarity bias hypothesis, which predicted emergence of priming for visually unfamiliar case-alternated targets.

\section{General discussion}

This study investigated the "familiarity bias" explanation of the absence of masked priming effect for nonwords in lexical decision and for Different responses in the samedifferent task. Bodner and Masson (1997) suggested that, in the lexical decision task, enhanced perceptual fluency due to masked priming is normally taken as evidence that the target is a word, which inhibits nonword decisions. Bowers (2010) extended this explanation to the same-different task, arguing that in this task the enhanced perceptual fluency due to masked priming is taken as evidence that the target has been repeated (i.e., the target is the same as the referent), and this conflicts with a Different response. The most direct support for the familiarity bias hypothesis to
Table 4 Mean decision latencies (RT, in ms), standard error (in parentheses) and percent error rates $(\% \mathrm{E})$ in Experiment 3 (same-different task, all unambiguous-letter stimuli)

Reference and targets were always in Courier 12 font. The Same-font primes were in Courier 12 font; Different-font primes were in Arial 10 font
Response

\begin{tabular}{lllllll}
\hline & Same & & & $\begin{array}{l}\text { Different } \\
\text { Example }\end{array}$ & RT & \%E \\
\hline Refime type & RT & \%Enple & & & usually/morNiNg & \\
Same-font identity & century & $406(10)$ & 2.8 & morning & $490(11)$ & 3.0 \\
Same-font control & supreme & $499(9)$ & 10.6 & airport & $489(10)$ & 2.2 \\
Priming effect & & 93 & 7.8 & & -1 & -0.8 \\
Different-font identity & century & $413(9)$ & 3.3 & morning & $486(10)$ & 4.7 \\
Different-font control & supreme & $491(8)$ & 10.5 & airport & $484(11)$ & 3.3 \\
Priming effect & & 78 & 7.2 & & -2 & -1.4 \\
\hline
\end{tabular}


date has come from Bodner and Masson's (1997) demonstration that presenting targets in a lexical decision task in cAsE-AlTeRnAtEd format produced a large priming effect for nonwords. (The priming effect for nonwords was numerically even larger than that for word targets.) Bodner and Masson (1997) suggested that when targets are presented in an unusual visual format, this should reduce "subjects' dependence on an immediate sense of familiarity in classifying the target" (p. 275). This eliminates the bias, leading to the emergence of nonword priming.

Experiment 1 used the stimuli used by Bodner and Masson (1997, Experiment 2a), and presented the targets in casealternated format in a lexical decision task. Primes (always in lowercase) were either presented in the same font as the target, or a different font. This was to test the possibility that the emergence of a priming effect for case-alternated nonwords is due to the physical continuity in half of the letters of the identity prime and the target. The physical continuity hypothesis was not supported, as nonword priming emerged with both the same-font primes and different-font primes. However, a post-hoc analysis showed that nonword priming was limited to targets containing an ambiguous letter (lowercase letter 1 , which is confusable with uppercase letter I).

Experiments 2 and 3 used a newly constructed set of cAsE-AlTeRnAtEd targets that did not contain an ambiguous letter. Experiment 2, using the lexical decision task, and Experiment 3, using the same-different task, showed robust priming for word targets and the Same responses, but no priming for nonword targets and Different responses. These findings show that presenting targets in a visually unfamiliar, cAsE-AlTeRnAtEd format is not sufficient to produce nonword priming.

It may be argued that the fact that we did not find nonword priming may have been due to our casealternation manipulation not being "strong enough" to make the stimuli sufficiently visually unfamiliar to discourage subjects from using the subjective sense of familiarity to bias decisions. ${ }^{4}$ But our case alternation manipulation used the same font (Courier 12) used by Bodner and Masson (1997), and in Experiment 1, we used their stimuli, and unlike their result, nonword priming was nowhere near

\footnotetext{
${ }^{4}$ Note, however, that exactly the opposite needs to be assumed to explain the discrepancy between two earlier studies (Besner, 1983; Kinoshita, 1987). Besner (1983) found that case alternation slowed down RTs for high-frequency words more than low-frequency words, and for words more than nonwords, and took this as support for the role of "familiarity detector" in lexical decision. In contrast, Kinoshita (1987) found an equal slowdown due to case alternation with words and nonwords, and with high-frequency and low-frequency words. The casealternation effect on nonwords was actually larger in the latter study ( $89 \mathrm{~ms}$ in Besner's study and $129 \mathrm{~ms}$ in Kinoshita's study). This pattern is exactly the opposite expected from the view that a stronger case alternation effect is needed to discourage subjects from using the subjective feeling of familiarity as a basis for making lexical decisions.
}

the size of word priming. ${ }^{5}$ Moreover, recall that Bodner and Masson (2001; Experiment 5b) themselves did not find a nonword priming effect with case-alternated targets. It seems more parsimonious to conclude that the original finding of a large nonword priming effect by Bodner and Masson (1997; Experiment 2a) may be an exception. Taken together, the empirical support for the familiarity bias hypothesis, based on the emergence of nonword priming for targets presented in a visually unfamiliar format, is weak.

\section{Reconsidering the familiarity bias hypothesis}

Our results provided little support for the prediction that presenting targets in an unusual visual format disrupts the operation of familiarity bias in lexical decision or the samedifferent task. This casts doubt on the claim that enhanced familiarity based on perceptual fluency due to masked priming biases lexical decision and the same-different decision when targets are presented in the standard (visually familiar) format.

Certainly, there have been demonstrations that enhanced perceptual fluency caused by masked priming is misattributed to another source, and biases decisions. For example, in an episodic recognition task, Rajaram (1993; Experiment 3 ) found that priming the targets at test increased the bias towards responding OLD for both old and new targets. Kinoshita (1997; Experiment 1) replicated this finding. The fact that these bias effects were observed only with the KNOW responses (operationally defined as OLD responses for which participants said were not accompanied by retrieval of contextual information) supports the idea that this reflects a bias in the "feeling of familiarity". So, why wasn't a similar bias effect found in the lexical decision task or the same-different task here?

\footnotetext{
${ }_{5}^{5}$ One noteworthy aspect of Bodner and Masson's (1997) Experiment $2 \mathrm{a}$ is that the RTs were unusually slow. In particular, mean nonword RTs were around $1,000 \mathrm{~ms}$ (compared to the mean nonword RT of $700-750 \mathrm{~ms}$ in the present Experiment 1 that used their stimuli, and 720-750 ms in Bodner \& Masson's [2001] Experiment 5b, that used different stimuli). As difference scores (priming effects) are expected to be magnified in slow responses on statistical and methodological grounds, this could potentially account for the emergence of nonword priming effect in Bodner and Masson's experiment. But, in the lexical decision task using orthographically legal nonwords of 4-7 letters like those used in these experiments, nonword RTs in excess of $1,000 \mathrm{~ms}$ are unusual. It is also of interest to note that in Bodner and Masson's (1997) Experiment 1 that presented these targets in the standard, uppercase format, the responses to the low-frequency words and nonwords were substantially (more than $100 \mathrm{~ms}$ ) slower than the RTs in Forster and Davis' (1984) Experiment 1 that used comparable stimuli (see their Table 1, p. 274.) That is, the subjects in Bodner and Masson's study (1997) were exceptionally slow at making lexical decisions compared to subjects in other studies. Perhaps this is because they did not know for certain whether (some of) these low-frequency words and nonwords were words or nonwords. In our Experiment 2, we avoided this problem by selecting those words that had a minimum lexical decision accuracy of 0.88 (mean 0.97) in the ELP Database.
} 
The key to finding a familiarity bias effect may not be in the different tasks used, but in the level of accuracy. Compared to the lexical decision task or the same-different task, accuracy was not very high in the episodic recognition studies described above. In Rajaram (1993), the hit rate was $63.5 \%$ and the false alarm rate was 20.5\%; in Kinoshita (1997), the hit rate was $70.2 \%$ and the false alarm rate was $7.3 \%$. In contrast to these studies, in a similar episodic recognition task, but one which produced a much higher level of accuracy, Forster (1985; Experiments 3 and 4) did not find a "familiarity bias" pattern. Consistent with the pattern found in the present experiments, masked priming facilitated RTs of OLD decisions but had no effect on the NEW decisions. In Forster's episodic recognition task, participants studied fewer items (20 nonwords in Experiment 3 and 30 words in Experiment 4, in comparison to 60 words in Rajaram and Kinoshita) under intentional study instruction, and as a result, accuracy was much higher (overall, the hit rate was $93.2 \%$ and false alarm rate $6.9 \%$ ). That is, misattribution of perceptual fluency to prior occurrence of the stimulus was observed when the level of episodic recognition was low, but not when it was high. Misattribution to prior occurrence has also been reported with other experimenter-induced perceptual fluency manipulations, such as presenting recognition test targets through visual noise (e.g., Johnston, Hawley, \& Elliott, 1991). As with the masked priming manipulation, misattribution of enhanced perceptual fluency to prior occurrence was found only when the level of episodic recognition was low (Johnston, Hawley, \& Elliott, 1991; noted in Kinoshita, 2003).

Misattribution of perceptual fluency to the wrong source is observed with other types of judgments such as liking. This is demonstrated in "the mere exposure effect", where prior presentation of items increases judgments of liking under conditions where the level of episodic recognition is minimal. Whittlesea and Price (2001) wondered why the same attribution of fluency is not found with episodic recognition judgments, if prior presentation increases perceptual fluency. They showed that the (mis)attribution in liking judgments resulted from using a "nonanalytic" strategy in liking judgments. When participants were forced to use a more analytic strategy to make liking judgments by being instructed to justify their selection, effects of prior exposure were eliminated. Conversely, when participants were encouraged not to scrutinize the source of their recognition judgments, prior exposure did increase recognition judgments. In other words, (mis)attribution of fluency is found: (1) when the required decision cannot be made accurately on the basis of evidence from the correct source, and (2) when participants adopt a "non-analytic" mode of decision-making, i.e., they do not scrutinize the provenance (source) of evidence used to make the decision.

From this perspective, there seems to be little reason to expect the misattribution of perceptual fluency, i.e., the key assumption of the familiarity bias hypothesis - to bias decisions in the lexical decision task and the same-different task. In general, accuracy in the lexical decision task and the same-different task is quite high, i.e., higher than in a typical episodic recognition task. Accuracy level in the present experiments expressed as "hit rates" and "false alarm rates" was $96.6 \%$ and $4.9 \%$ in the lexical decision task (Experiment 2) and $93.2 \%$ and $3.3 \%$ in the same-different task (Experiment 3). In lexical decision, if word targets are selected to be familiar to subjects (as was done in the present Experiment 2 by selecting items that had a minimum lexical decision accuracy of 0.88 from the ELP Database, with a mean of 0.97), subjects should have little difficulty discriminating between words and nonwords. In the same-different task, the referent is presented clearly, and participants have 1 second to encode the item in working memory. Deciding if a target is the same or different from the referent is therefore trivially easy. To put it another way, both the decision that a letter string is a word, and that it is the same as the referent, can be made accurately on the basis of evidence from the correct source, i.e., the perceptual input from the target. For lexical decision and the same-different task performed under typical conditions then, there would be little reason to expect the subjective sense of familiarity to bias decisions, contrary to the familiarity bias hypothesis as put forward by Bodner and Masson (1997) and Bowers (2010).

\section{Conclusion}

Priming is generally absent for nonword targets in lexical decision and for Different responses in the same-different task, in contrast to robust priming effects observed with the word targets and Same responses. Norris and Kinoshita's (2008) Bayesian Reader account provides a unified explanation for this finding, in terms of how the evidence accumulated by the prime contributes towards the decision required to the target. This pattern did not change when case-alternated targets with unambiguous letters were presented. These results provide no support for the "familiarity-bias" hypothesis proposed by Bodner and Masson (1997) for the lexical decision task and that was extended to the same-different task by Bowers (2010). We conclude that the absence of a masked priming effect in either lexical decision or the same-different task is explained better by the Bayesian Reader account.

Acknowledgments Thanks are due to Betty Mousikou for research assistance. We would also like to thank the reviewers, in particular, Mike Masson, and the action editor Dave Huber for their helpful comments, and SK would like to thank Ken Forster for discussion of Bodner and Masson's (1997) results that led to Experiment 1. This research was supported by the Australian Research Council Discovery Project grant (DP0877084) to Sachiko Kinoshita and Dennis Norris. 
Appendix A

Table 5 Critical stimuli used in Experiment 2 (lexical decision)

\begin{tabular}{|c|c|c|c|c|c|}
\hline \multicolumn{3}{|l|}{ Words } & \multicolumn{3}{|l|}{ Nonwords } \\
\hline target & identity & control & target & identity & control \\
\hline cEnTuRy & century & supreme & pOrFiNg & porfing & trosect \\
\hline wEsTeRn & western & divorce & sMiEnGe & smienge & doreber \\
\hline $\mathrm{rEsPeCt}$ & respect & tragedy & $\mathrm{fEaBiNg}$ & feabing & smienge \\
\hline bAlAnCe & balance & victory & dOmEoLe & domeole & signigy \\
\hline rEqUiRe & require & stretch & fApAgEr & falager & porfing \\
\hline vIcToRy & victory & respect & pHaPtEr & phapter & oirdort \\
\hline $\mathrm{aDvAnCe}$ & advance & western & fOmEdOw & fomedow & digance \\
\hline sUpReMe & supreme & premier & flgEaSe & figease & dontest \\
\hline tRaGeDy & tragedy & require & gEnTiOn & gention & frofest \\
\hline iNsTaNt & instant & poverty & $\mathrm{dOrEbEr}$ & doreber & phapter \\
\hline oRgAnIc & organic & mistake & sObIgHt & sobight & figease \\
\hline mIsTaKe & mistake & instant & sIgNiGy & signigy & domeole \\
\hline eXaMiNe & examine & insight & tRoSeCt & trosect & feabing \\
\hline aNxIoUs & anxious & examine & dIgAnCe & digance & falager \\
\hline dIvOrCe & divorce & organic & dAcIfIc & dacific & gention \\
\hline sTrEtCh & stretch & circuit & dEeKoNd & deekond & fomedow \\
\hline pReMiEr & premier & century & $\mathrm{dOnTeSt}$ & dontest & fearost \\
\hline cIrCuIt & circuit & balance & fEaRoSt & fearost & sobight \\
\hline iNsIgHt & insight & anxious & fRoFeSt & frofest & deekond \\
\hline pOvErTy & poverty & advance & oIrDoRt & oirdort & dacific \\
\hline vArIoUs & various & pioneer & aUtMiDe & autmide & srinary \\
\hline fOrEiGn & foreign & variety & fUsGaNd & fusgand & smondor \\
\hline sErIoUs & serious & uniform & dOrVaRd & dorvard & singtom \\
\hline kItChEn & kitchen & stomach & sRiNaRy & srinary & feventh \\
\hline vArIeTy & variety & stadium & dAtIeNt & datient & nuspect \\
\hline eXtReMe & extreme & serious & fEcEiNe & feceine & jighway \\
\hline $\mathrm{pErFeCt}$ & perfect & various & sEaPhEr & seapher & ixdense \\
\hline uNiFoRm & uniform & physics & $\mathrm{fErCeNt}$ & fercent & isotion \\
\hline dEsTrOy & destroy & kitchen & iXdEnSe & ixdense & gendure \\
\hline iMpRoVe & improve & perfect & jIgHwAy & jighway & fusgand \\
\hline sToMaCh & stomach & destroy & fEdErVe & federve & datient \\
\hline dIsPuTe & dispute & harmony & $\mathrm{dOnSeXt}$ & donsext & seapher \\
\hline hArMoNy & harmony & improve & iSoTiOn & isotion & federve \\
\hline dEnSiTy & density & perform & fEvEnTh & feventh & drisute \\
\hline pErFoRm & perform & justify & $\mathrm{nUsPeCt}$ & nuspect & feceine \\
\hline jUsTiFy & justify & extreme & altMoOr & aitmoor & dorvard \\
\hline sTaDiUm & stadium & dispute & sInGtOm & singtom & donsext \\
\hline aCaDeMy & academy & foreign & dRiSuTe & drisute & fercent \\
\hline pHySiCs & physics & density & sMoNdOr & smondor & autmide \\
\hline pIoNeEr & pioneer & academy & gEnDuRe & gendure & aitmoor \\
\hline sUrFaCe & surface & observe & tRiFaTe & trifate & dartner \\
\hline sUbJeCt & subject & triumph & sUrDoSe & surdose & dresare \\
\hline $\mathrm{mAcHiNe}$ & machine & surface & nAtTeRn & nattern & durlish \\
\hline $\mathrm{mEaSuRe}$ & measure & subject & fOnCeRn & foncern & engappy \\
\hline sTrAnGe & strange & citizen & $\mathrm{mOnCePt}$ & moncept & faxinum \\
\hline
\end{tabular}


Table 5 (continued)

\begin{tabular}{|c|c|c|c|c|c|}
\hline \multicolumn{3}{|l|}{ Words } & \multicolumn{3}{|l|}{ Nonwords } \\
\hline bEnEfIt & benefit & storage & fAxInUm & faxinum & henuine \\
\hline eViDeNt & evident & compare & pInIsUm & pinisum & fenapor \\
\hline aChIeVe & achieve & operate & fAyHeNt & fayhent & stracdo \\
\hline oPeRaTe & operate & benefit & sEqUeSt & sequest & gixture \\
\hline sToRaGe & storage & nervous & fEnApOr & fenapor & trifate \\
\hline dIsTaNt & distant & measure & sMeViEs & smevies & itosian \\
\hline rOuTiNe & routine & veteran & $\mathrm{dReSaRe}$ & dresare & moncept \\
\hline cOuRaGe & courage & evident & hEnUiNe & henuine & nattern \\
\hline cItIzEn & citizen & routine & dArTnEr & dartner & pinisum \\
\hline $\mathrm{cOmPaRe}$ & compare & despair & gIxTuRe & gixture & pusdard \\
\hline vEtErAn & veteran & courage & dUrLiSh & durlish & sequest \\
\hline oBsErVe & observe & distant & eNgApPy & engappy & smevies \\
\hline nErVoUs & nervous & strange & sTrAcDo & stracdo & fayhent \\
\hline tRiUmPh & triumph & machine & iToSiAn & itosian & surdose \\
\hline $\mathrm{dEsPaIr}$ & despair & achieve & pUsDaRd & pusdard & foncern \\
\hline iNsTeAd & instead & version & nEcTiOn & nection & darfare \\
\hline pIcTuRe & picture & opinion & fUnDrEd & fundred & dassive \\
\hline oPiNiOn & opinion & picture & sMaTiOn & smation & detsork \\
\hline oBvIoUs & obvious & fortune & fEsPiTe & fespite & dontact \\
\hline eCoNoMy & economy & obvious & $\mathrm{dReGeNt}$ & dregent & oiccome \\
\hline aNcIeNt & ancient & protein & fEaShEr & feasher & dromote \\
\hline aBsEnCe & absence & horizon & $\mathrm{dOnTaCt}$ & dontact & smation \\
\hline vErSiOn & version & gesture & hOrTiOn & hortion & feasher \\
\hline cOnTaIn & contain & exhibit & gIcTiOn & giction & fespite \\
\hline aNxIeTy & anxiety & eastern & $\mathrm{dArFaRe}$ & darfare & fespond \\
\hline eDiTiOn & edition & feature & sOrShIp & sorship & fundred \\
\hline fEaTuRe & feature & edition & wEvEnUe & wevenue & giction \\
\hline gEsTuRe & gesture & economy & dAsSiVe & dassive & hortion \\
\hline eAsTeRn & eastern & instead & dRoMoTe & dromote & imaceur \\
\hline hOrIzOn & horizon & dynamic & dEtSoRk & detsork & mogable \\
\hline $\mathrm{aCqUiRe}$ & acquire & contain & $\mathrm{dOsHeRe}$ & doshere & nection \\
\hline fOrTuNe & fortune & anxiety & olcCoMe & oiccome & dregent \\
\hline eXhIbIt & exhibit & ancient & iMaCeUr & imaceur & doshere \\
\hline dYnAmIc & dynamic & acquire & fEsPoNd & fespond & sorship \\
\hline pRoTeIn & protein & absence & $\mathrm{mOgAbLe}$ & mogable & wevenue \\
\hline
\end{tabular}


Appendix B

Table 6 Critical stimuli used in Different trials in Experiment 3 (same-different task)

\begin{tabular}{|c|c|c|c|}
\hline reference & target & identity & control \\
\hline usually & mOrNiNg & morning & airport \\
\hline exactly & sCiEnCe & science & chapter \\
\hline council & mEaNiNg & meaning & dignity \\
\hline village & sOmEoNe & someone & contest \\
\hline shelter & mAnAgEr & manager & disease \\
\hline welfare & $\mathrm{cHaPtEr}$ & chapter & finance \\
\hline process & sOmEhOw & somehow & manager \\
\hline suppose & dIsEaSe & disease & meaning \\
\hline summary & mEnTiOn & mention & forever \\
\hline emperor & fOrEvEr & forever & pacific \\
\hline proceed & tOnIgHt & tonight & science \\
\hline stature & dIgNiTy & dignity & nearest \\
\hline defense & pRoTeCt & protect & somehow \\
\hline beneath & fInAnCe & finance & protect \\
\hline conduct & pAcIfIc & pacific & weekend \\
\hline quarter & wEeKeNd & weekend & protest \\
\hline farther & cOnTeSt & contest & mention \\
\hline ability & $\mathrm{nEaReSt}$ & nearest & someone \\
\hline satisfy & pRoTeSt & protest & tonight \\
\hline sincere & aIrPoRt & airport & morning \\
\hline million & oUtSiDe & outside & context \\
\hline quality & hUsBaNd & husband & emotion \\
\hline talking & fOrWaRd & forward & expense \\
\hline consist & pRiMaRy & primary & husband \\
\hline typical & pAtIeNt & patient & outdoor \\
\hline formula & rEcEiVe & receive & highway \\
\hline support & wEaThEr & weather & kingdom \\
\hline officer & $\mathrm{pErCeNt}$ & percent & forward \\
\hline illness & eXpEnSe & expense & outside \\
\hline attract & hIgHwAy & highway & patient \\
\hline battery & rEsErVe & reserve & tribute \\
\hline succeed & cOnTeXt & context & seventh \\
\hline student & eMoTiOn & emotion & receive \\
\hline tension & sEvEnTh & seventh & primary \\
\hline unknown & $\mathrm{sUsPeCt}$ & suspect & weather \\
\hline mankind & oUtDoOr & outdoor & sponsor \\
\hline factory & kInGdOm & kingdom & percent \\
\hline optimum & tRiBuTe & tribute & reserve \\
\hline theorem & sPoNsOr & sponsor & venture \\
\hline tourist & vEnTuRe & venture & suspect \\
\hline finally & pRiVaTe & private & concept \\
\hline herself & pUrPoSe & purpose & concern \\
\hline capital & pAtTeRn & pattern & furnish \\
\hline essence & cOnCeRn & concern & private \\
\hline rapidly & cOnCePt & concept & maximum \\
\hline
\end{tabular}

Table 6 (continued)

\begin{tabular}{|c|c|c|c|}
\hline reference & target & identity & control \\
\hline equally & mAxImUm & maximum & payment \\
\hline written & mInImUm & minimum & partner \\
\hline current & pAyMeNt & payment & mustard \\
\hline warrant & rEqUeSt & request & minimum \\
\hline cottage & sEnAtOr & senator & pattern \\
\hline payroll & sPeCiEs & species & unhappy \\
\hline concert & $\mathrm{pRePaRe}$ & prepare & tractor \\
\hline project & gEnUiNe & genuine & mixture \\
\hline confirm & pArTnEr & partner & genuine \\
\hline promise & mIxTuRe & mixture & request \\
\hline mystery & fUrNiSh & furnish & senator \\
\hline theatre & uNhApPy & unhappy & species \\
\hline destiny & tRaCtOr & tractor & purpose \\
\hline collect & uToPiAn & utopian & prepare \\
\hline transit & mUsTaRd & mustard & utopian \\
\hline popular & sEcTiOn & section & amateur \\
\hline meeting & hUnDrEd & hundred & contact \\
\hline clothes & sTaTiOn & station & notable \\
\hline quickly & dEsPiTe & despite & portion \\
\hline unusual & $\mathrm{pReVeNt}$ & prevent & hundred \\
\hline billion & $\mathrm{tEaChEr}$ & teacher & massive \\
\hline freedom & $\mathrm{cOnTaCt}$ & contact & network \\
\hline account & pOrTiOn & portion & revenue \\
\hline sheriff & fIcTiOn & fiction & nowhere \\
\hline produce & wArFaRe & warfare & outcome \\
\hline feeling & wOrShIp & worship & prevent \\
\hline pottery & rEvEnUe & revenue & fiction \\
\hline product & mAsSiVe & massive & section \\
\hline captain & pRoMoTe & promote & respond \\
\hline anybody & nEtWoRk & network & worship \\
\hline sixteen & nOwHeRe & nowhere & despite \\
\hline tangent & oUtCoMe & outcome & station \\
\hline compete & aMaTeUr & amateur & promote \\
\hline cockpit & rEsPoNd & respond & warfare \\
\hline pursuit & nOtAbLe & notable & teacher \\
\hline
\end{tabular}

\section{References}

Balota, D. A., Yap, M. J., Cortese, M. J., Hutchison, K. A., Kessler, B., Loftis, B., Neely, J. H., Nelson, D. L., Simpson, G. B., \& Treiman, R. (2007). The English Lexicon Project. Behavior Research Methods, 39, 445-459. Available at http://elexicon. wustl.edu/

Besner, D. (1983). Basic decoding components in reading: Two dissociable feature extraction processes. Canadian Journal of Psychology, 37, 429-438.

Bodner, G. E., \& Masson, M. E. J. (1997). Masked repetition priming of words and nonwords: Evidence for a nonlexical basis for priming. Journal of Memory and Language, 37, 268-293. 
Bodner, G. E., \& Masson, M. E. J. (2001). Prime validity affects masked repetition priming: Evidence for an episodic resource account of priming. Journal of Memory and Language, 45, 616-647.

Bowers, J. S. (2010). Does masked and unmasked priming reflect Bayesian inference as implemented in the Bayesian Reader? European Journal of Cognitive Psychology, 22, 779-797.

Coltheart, M., Davelaar, E., Jonasson, J. T., \& Besner, D. (1977). Access to the internal lexicon. In S. Dornic (Ed.), Attention and Performance, VI (pp. 535-555). Hillsdale: Erlbaum.

Davis, C. J. (2003). Factors underlying masked priming effects in competitive network models of visual word recognition. In S. Kinoshita \& S. J. Lupker (Eds.), Masked priming: The state of the art (pp. 121-170). New York: Psychology Press.

Forster, K. I. (1985). Lexical acquisition and the modular lexicon. Language and Cognitive Processes, 1, 87-108.

Forster, K. I. (1998). The pros and cons of masked priming. Journal of Psycholinguistic Research, 27, 203-233.

Forster, K. I., \& Davis, C. (1984). Repetition priming and frequency attenuation in lexical access. Journal of Experimental Psychology. Learning, Memory, and Cognition, 10, 680-698.

Forster, K. I., \& Forster, J. C. (2003). DMDX: A Windows display program with millisecond accuracy. Behavior Research Methods, Instruments, \& Computers, 35, 116-124.

Forster, K. I., Mohan, K., \& Hector, J. (2003). The mechanics of masked priming. In S. Kinoshita \& S. J. Lupker (Eds.), Masked priming: The state of the art (pp. 3-37). Hove: Psychology Press.

Grainger, J. (2008). Cracking the orthographic code: An introduction. Language and Cognitive Processes, 23, 1-35.

Huber, D. E., Shiffrin, R. M., Lyle, K. B., \& Quach, R. (2002). Mechanisms of source confusion and discounting in short-term priming 2: Effects of prime similarity and target duration. Journal of Experimental Psychology. Learning, Memory, and Cognition, 28, 1120-1136.

Johnston, W. A., Hawley, K. J., \& Elliott, J. M. G. (1991). Contribution of perceptual fluency to recognition memory judgments. Journal of Experimental Psychology. Learning, Memory, and Cognition, 17, 210-233.

Kinoshita, S. (1987). Case alternation effect: Two types of word recognition?'. The Quarterly Journal of Experimental Psychology, 39A, 701-720.

Kinoshita, S. (1997). Masked target priming effects on feeling-ofknowing and feeling-of-familiarity judgments. Acta Psychologica, 97, 183-199.

Kinoshita, S. (2003). Familiarity in an implicit and explicit memory task: A common mechanism. In J. S. Bowers \& C. J. Marsolek (Eds.), Rethinking implicit memory (pp. 284-301). Oxford: Oxford University Press.

Kinoshita, S., \& Lupker, S. J. (Eds.). (2003). Masked priming: The state of the art. Hove: Psychology Press.
Kinoshita, S., \& Norris, D. (2009). Transposed-letter priming of orthographic representations. Journal of Experimental Psychology. Learning, Memory, and Cognition, 35, 1-18.

Kinoshita, S., \& Norris, D. (2010). Masked priming effect reflects evidence accumulated by the prime. The Quarterly Journal of Experimental Psychology, 63, 194-204.

Kucera, H., \& Francis, W. N. (1967). Computational analysis of presentday American English. Providence: Brown University Press.

Marzouki, Y., \& Grainger, J. (2008). Effects of prime and target eccentricity on masked repetition priming. Psychonomic Bullein \& Review, 15, 141-148.

Norris, D. (2006). The Bayesian Reader: Explaining word recognition as an optimal Bayesian decision process. Psychological Review, 113, 327-357.

Norris, D. (2009). Putting it all together: A unified account of word recognition and reaction-time distributions. Psychological Review, 116, 207-219.

Norris, D., \& Kinoshita, S. (2008). Perception as evidence accumulation and Bayesian inference: Insights from masked priming. Journal of Experimental Psychology: General, 137, 433-455.

Perea, M., \& Lupker, S. J. (2003). Transposed-letter confusability effects in masked form priming. In S. Kinoshita \& S. J. Lupker (Eds.), Masked priming: State of the art (pp. 97-120). Hove: Psychology Press.

Rajaram, S. (1993). Remembering and knowing: Two means of access to the personal past. Memory \& Cognition, 21, 89-102.

Ratcliff, R., Gomez, P., \& McKoon, G. (2004). A diffusion model account of the lexical decision task. Psychological Review, 111, 159-182.

Schoonbaert, S., \& Grainger, J. (2004). Letter position coding in primed word perception: Effects of repeated and transposed letters. Language and Cognitive Processes, 19, 333-367.

Wagenmakers, E.-J., Steyvers, M., Raaijmakers, J. G. W., Shiffrin, R. M., van Rijn, H., \& Zeelenberg, R. (2004). A model for evidence accumulation in the lexical decision task. Cognitive Psychology, 48, 332-367.

Whittlesea, B. W. A., \& Price, J. R. (2001). Implicit/explicit memory versus analytic/nonanalytic processing: Rethinking the mere exposure effect. Memory \& Cognition, 29, 234-246.

Yap, M. J., Balota, D. A., Tse, C.-S., \& Besner, D. (2008). On the additive effects of stimulus quality and word frequency in lexical decision: Evidence for opposing interactive influences revealed by RT distributional analysis. Journal of Experimental Psychology. Learning, Memory, and Cognition, 34, 495-513.

Yap, M. J., Tse, C.-S., \& Balota, D. A. (2009). Individual differences in the joint effects of semantic priming and word frequency revealed by RT distributional analyses: The role of lexical integrity. Journal of Memory and Language, 61, 303325 . 